\title{
A Student Panel Discussion to Practice Argumentation Skills
}

\author{
Miriam Gensowski, Assistant Professor, Department of Economics, University of \\ Copenhagen
}

Article reviewed by the editors

\section{Abstract}

Economics students are used to lectures of the "chalk-and-talk" variety. In this project, I develop, describe, and evaluate a pedagogical intervention that provides students with the opportunity to practice their argumentation skills. The development of these skills is not usually part of the core curriculum. For this project, a panel discussion format is used to enable students to develop arguments using empirical evidence, and generally navigate a space where there is no single right or wrong answer. The peer-learning environment allows students to develop argumentation and evaluation skills in a setting where they receive informal formative assessment.

\section{Introduction: The Need for Practice of Argumentation Skills}

The typical university class in economics teaches students a very specific set of skills: understanding formal economic models, and solving a well-defined problem that the teacher gives them, using maths to show they master the technical aspects. This means that typical economics students develop strong skills in this particular domain. But once they start their jobs as economists - be it in banks, consulting, government service, or research - they will be expected to evaluate messy real-world issues, decide which economic model is useful to analyze a given problem, know how to use data and empirical evidence to form an opinion, make arguments for or against a certain solution, and most importantly, communicate these arguments to laymen and professionals. This can be very challenging if students are used to neat models and problems presented in a way that suggests right and wrong answers. They often have not had many opportunities to practice their economic argumentation skills, and they are not used to navigating ambiguous spaces where even the problem setting is uncertain.

With the objective of addressing this need for a different type of skill set, and to benefit from the occasion of teaching a topic that raises many applied policy questions, I developed the course "Economics of Education" to have a professional training component. Specifically, I wanted to let students develop argumentation skills by giving them plenty of opportunities for practice and rehearsal. In this study, I develop, describe, and evaluate a pedagogical intervention that offers one type of 
opportunity for practice: a student panel discussion with role play, where three teams present and defend certain positions in a debate about the merits of a particular explanation for observed wage-patterns in economics, described as the Skill-biased technological change hypothesis. This student activity engaged students with a meaningful, relevant task that exposed them to a "messy" topic where they would need to draw on empirical evidence and test out their arguments against counter-arguments. This was a dry run not only for the exam, where they would have to employ these skills, but also for any job in which they have to communicate economic matters in a social setting.

My motivation for this exercise, and its analysis, is based on the idea that students cannot develop skills without the opportunity to practice them. Most teaching in economics follows the standard "chalk-and-talk" model (Becker and Watts, 2001), including many lectures in my course, which means another component of learning and practice is needed if the students are to develop the argumentation skills they will need in the future.

As proposed by the theory of constructive alignment (Biggs and Tang, 2007), the activities in class should train students to develop skills that are needed in the final assessment. The final exam should, therefore, assess the 'intended learning outcomes' of the course. What are these learning outcomes for the course in question?

This course will teach students how to apply economic thinking to educationrelated questions. [...] After taking this course, students should be able to evaluate education policy issues methodically and to apply economic theories to address education questions as a well-trained economist.

[...] students are expected to

- Communicate their theory-based arguments orally and in written form. Construct concise cases where they show their well-rounded appraisal of the situation that connects theory to the real world, and use empirical evidence to support these cases.

- Read selected articles in the current literature, and examine whether the presented empirical evidence convincingly identifies causal relationships (Biggs and Tang, 2007).

These intended learning outcomes clearly place high demands on the students. ${ }^{1}$ I expected students to struggle with this challenge to develop their argumentation

\footnotetext{
${ }^{1}$ The development of assessments of real-world issues and the construction of arguments require students to perform at the high levels of the SOLO taxonomy developed by Biggs and Tang (2007) - at the "relational level" at the very least, if not at the "Extended abstract" level.
} 
skills, and they did. Some students reacted with outcries such as "just give us a model to solve!."

I begin my article by describing the details of the panel discussion (Section 2), and then outline how this specific exercise corresponds to the theory of Assessment for Learning (Sambell et al., 2013), in Section 3. In Section 4 I present a critical assessment of the panel discussion, to test whether this particular opportunity for practice was as productive as intended. I also probe whether the specific exercise was perceived by students as an effective way to practice relevant skills.

\section{Implementation of the Panel Discussion}

In order to let students practice their argumentation skills, I chose a topic where discussion and criticism are necessary and frequent among professional economists. The hypothesis of skill-biased technological change (SBTC) posits that technological change, which complements skilled labor, can explain secular increases in skill premia (higher earnings for more highly skilled workers, with an increasing difference when compared with lower skilled workers), and wage inequality within education groups. The prime example for this type of technological change is the advent of computers. While this may sound obvious to the casual observer, there are many puzzles that this hypothesis fails to explain. Still today, economists do not agree whether the SBTC hypothesis is the right explanation for observed wage trends. I wanted to let the students experience the multitude of arguments and opinions related to this question, and learn to a) observe how experts construct arguments, b) evaluate arguments made by their peers, and c) develop their own arguments.

In order to prepare for the panel discussion on the SBTC hypothesis, students were asked to individually read one article each, from a list on this topic that I provided. This "division of labor" among students was to ensure a near-complete coverage of the relatively extensive field while breaking down the task into a manageable size for the individual student - the students in this elective class range from 2nd year bachelor's to master's students already beginning their theses, and includes exchange students as well. Not all of them would be comfortable with reading scientific journal articles on their own. ${ }^{2}$ In addition to limiting the reading to one article, I guided their reading by asking them to focus on one of the three main themes: 1) data describing main trends and issues, 2) arguments in favor of the SBTC hypothesis, and 3) arguments against. Some articles represented mainly one of the three themes, others contained a variety of arguments so that students had to select and categorize them into the themes. Especially "data" arguments were likely

\footnotetext{
${ }^{2}$ An added benefit of students each reading a different article was that they would feel increased ownership and responsibility for ensuring the coverage of the position presented in "their" article.
} 
present in most articles, and not necessarily in opposition to the other two positions, but as supporting evidence. Separating the themes served to highlight how professional economists use different ingredients to buffer their positions, and how they react to arguments made by other economists. Students were to summarize the arguments presented, and take notes on how these arguments were made. This oriented reading was practice for extracting relevant information from scientific texts.

I expected that some students might not have a lot of experience presenting in front of others, so to keep the environment as stress-free as possible, it was announced that in class, students would group together by main theme. They would discuss and agree on main points in their small groups, and then present their opinions "as a group" without lecture slides or a formal presentation. This way, no single student would stand out, and the really shy ones could participate in the small group without having to face the entire class.

As students arrived for the class, they grouped together and were given 20 minutes to discuss their findings and prepare statements. During that time, I moved around and was available for questions, but only few arose. I did, however, encourage them to keep the more complex issues in mind and to raise them during the discussion. When we began the actual discussion, I put up a slide on the projector that summarized the questions listed in the task assignment. For example, the group on "Data" was encouraged to go through the list and "Describe observed trends in relative wages, inequality (between- and within-education inequality)," or "Compare US data to European countries." One student began summarizing the entire paper she had read, without much regard for the level of knowledge of the other students (who had not read her particular paper). I did not want to interrupt her and stop the flow, but after she thought she was finished I asked several clarifying questions to reveal important aspects that she glossed over or did not explain well enough. These types of questions, at the "lower order" part of the learning spectrum, established a common understanding and the basis for further explorations of the topic. It remedied the students' own lack of pedagogical experience. Gradually, the groups began discussing. Once or twice I found the "opposing teams" to be too accommodating. In these cases, I asked investigative questions that challenged agreement, and highlighted contradictions. This encouraged students to come forward with contradicting evidence or arguments that I knew the learners should have found in their given readings.

All the while during the discussion, I kept notes on my laptop, projecting them on the screen. I asked students to provide me with key phrases that reflected their positions, and wrote only the student-defined summary points. They were made available to all students after the discussion, to allow them to revise their positions against the overview of positions mentioned. 
One aspect about this "lecture" stood out: Class participation dropped by over $50 \%$ for this particular session, relative to usual attendance. Only 8 students participated. Therefore, Section 4.3 will explicitly address absenteeism for this session.

\section{Theory}

My course aims to prepare students to enter the discipline of economics of education, and to facilitate their engagement with the discourse that economists hold there. As Sambell et al. (2013) put it, "mastering a field of knowledge involves not only learning about the subject matter, but also learning, eventually, to become a full participant in the field" (p. 52). Becoming a participant implies learning to think in the complex ways that a well-rounded economist does.

While some of the students in this class were at the Bachelor's level, I do not think it was too early to expose them to this aspect of our science. Eventually, they would have to learn how to engage with others on economic topics. This panel discussion allowed them to emulate high-quality arguments as they are exchanged in the literature, apprentice-style. As already mentioned in the introduction, I expect students to develop their argumentation skills in this course. But how can they improve the quality of their economic arguments, if they do not know what constitutes quality? They were expected to observe quality arguments in the selection of articles I had provided (as the expert). But emulation was not the only mechanism by which students were expected to practice high quality argumentation.

A theory that resounded strongly with the objectives of my pedagogical intervention is that of Assessment for Learning by Sambell et al. (2013). A central concept is formative assessment, essentially practice before the real assessment, such as "dry runs" or "mock exams." A crucial ingredient is the "assessment" or feedback part that provides an evaluation of how well students are doing in meeting the learning goals. Participation in our panel discussion provided such formative practice because students were expected to prepare their ideas of what constituted good arguments in the debate, they would then voice them, and see how they held up against contradicting opinions, and the critique of their peers. In cases when the opposing teams were too accommodating, I acted as a "quality check of last resort" to point out weaknesses in the lines of argumentation.

Sambell et al. (2013) emphasize that formative assessment can encourage students to spend time on task and engage in complex learning (Biggs and Tang, 2007, would likely call this "deep learning"). The authors argue that these opportunities to practice and to receive forward-oriented feedback are important for students because "most people actually learn by doing" and it means that students will not take part in a specific task or exercise for the first time during their summative assessment (the final exam). Formative assessment can be formal or informal, with 
social interaction as a substantial component of informal formative assessment (Chapters 4 and 5 in Sambell et al., 2013), as exemplified by the panel discussion. Sambell et al. (2013) also highlight two other characteristics of productive practice environments:

1. Learners need time and space to try things out. This means that constructive learning is favored in low-stakes formative environments. Students can sometimes find feedback debilitating, as highlighted by Molloy and Boud (2014). Our discussion was low-stakes because students were not graded or evaluated formally by the professor. But students were expected to speak up, so very shy students may have found this challenging. All students had the support of their peers throughout the activity and in general, I established a welcoming atmosphere in the classroom, actively encouraging student contributions (be they in the form of questions, answers, or comments).

2. Based on the view that knowledge is socially constructed, "opportunities for practice and rehearsal are arguably most productive when they involve some form of social exchange or social interaction" (Ch.3). The social interaction in itself constitutes an assessment: "By hearing what other people think of their ideas, and listening to how others - staff and students alike - express the sense they make of a topic, helps novices realize when they do not fully understand the ideas that emerge from a discussion or shared activity" ( $p$. 63). By discussing openly, each student saw the others' work "on display," and could thus compare this to their own arguments, and evaluate what worked well and what did not. This can provide indirect feedback without the individual student being addressed directly. I was also hoping that by engaging with their peers' reading of the literature, students would be confronted with new perspectives that would challenge their thinking about arguments.

The specific activity I had designed for the course on the SBTC hypothesis thus incorporated both of these characteristics. It was crucial to let students try out voicing their ideas against the other groups, because this trial and error generates progress. Only when students experience a misconception or realize their argument is under-developed can they identify areas for improvement. Experiencing both good and bad examples can be part of the task that ultimately fosters student learning (Knight and Yorke, 2003).

In conclusion, the panel discussion allowed students to practice communication, exercise judgments, weigh alternative explanations, and defend a chosen stance against peers by drawing on data and theory. By reading scientific articles, with guidance from the instructor, they could absorb the implicit expectations of what are convincing arguments, or how the discipline uses data to make them. Students also 
learned by imitating the experts. The peer learning is not only a productive addition to teacher-provided feedback, but also models real-world situations that students will experience in employment and in life more generally.

\section{Evaluation}

As Biggs and Tang (2007) explain, our teaching becomes most effective when we employ the best level of thinking about teaching (Ch. 2). In order to find out what works best, we need to focus on what the student does, to find out how they engage in activities that promote deep learning. Therefore, I supplement my own impression of the class (Section 4.1) with information from students (Sections 4.2 to 4.3).

\subsection{First Impression During Exercise}

My impression of the exercise was positive: students engaged seriously with the task. During the preparation phase in class, when confusion arose within the groups, they discussed among themselves and drew on their different readings of the articles. It was clear that students were the actors most responsible for the outcome of the exercise. We had a fruitful panel discussion that let students use data and arguments to engage with the topic. It even let students shine who were usually too quiet to be noticed. The chance for them to be the expert, and to teach their peers what they had learned, seemed to be empowering. At the same time, students were clearly inexperienced with this type of panel discussion. Therefore, I would expect them to improve and learn more from challenging each other if they had more opportunities to have these panel discussions.

I would recommend to other teachers implementing these activities to let students practice discussions more frequently - for example, the panel situation could be implemented during exercise classes with the teaching assistant. Also, since the success of the discussion hinges on the students' preparation, I found it very important to communicate to students that they were responsible for their own as well as their fellow students' learning progress - that they would learn from each other the subject matter. Also, I highlighted that the discussion would be practice for the type of arguments they were expected to construct in a final exam. This increased the perceived value of the exercise to the students, so they came to the discussion prepared - both prepared to participate and to experience a new classroom activity.

\subsection{Student Appraisal}

I developed a survey that students filled out either in class or on our online forum. I obtained 27 responses in total, out of 28 students who took the exam. Among the students who actually participated in the class exercise, I asked six questions to appraise the pedagogical intervention. Each item asked "On a scale of 1 to 10, how much are the following statements true:..." (10 being the greatest possible agreement). Participants were quite satisfied with the class itself (Fig.1.a), except for one student. 
They all agreed to have learned material that went beyond the one paper they had prepared on their own (Fig.1.b). ${ }^{3}$ I was concerned that students could be confused by the unmitigated ambiguity of the state of the literature, and a possibly "messy" discussion of it. But Fig.1.c shows that students did not feel confused by the discussion. The evaluation of how happy students were with what they learned is a little more mixed (Fig.1.d). While the majority was satisfied, two students only agreed moderately ( 4 and 5). Did they think they would have learned more from the instructor (me) than from their peers? No, students are not quite sure that they would have learned more from a lecture (Fig.1.e), and tended to be in favor of the student-led discussion (Fig.1.f).

\footnotetext{
${ }^{3}$ Note that the student with the lowest score on "enjoyment" is not the student who agreed least with having learned material beyond their own paper.
} 
Fig. 1.a

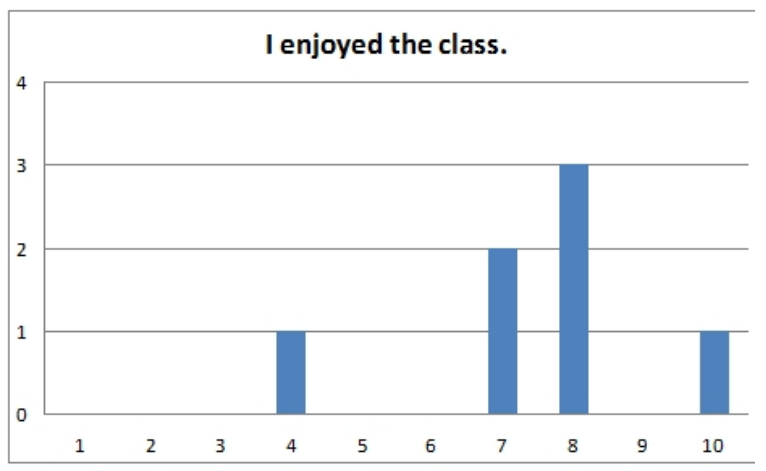

Fig. 1.C

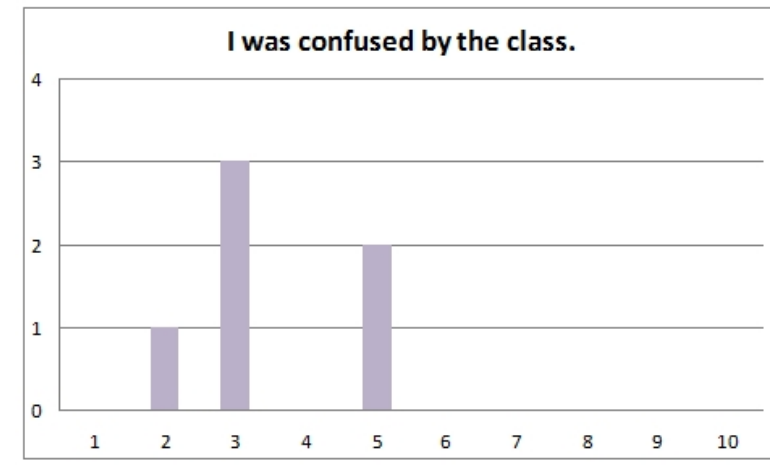

Fig. 1.e

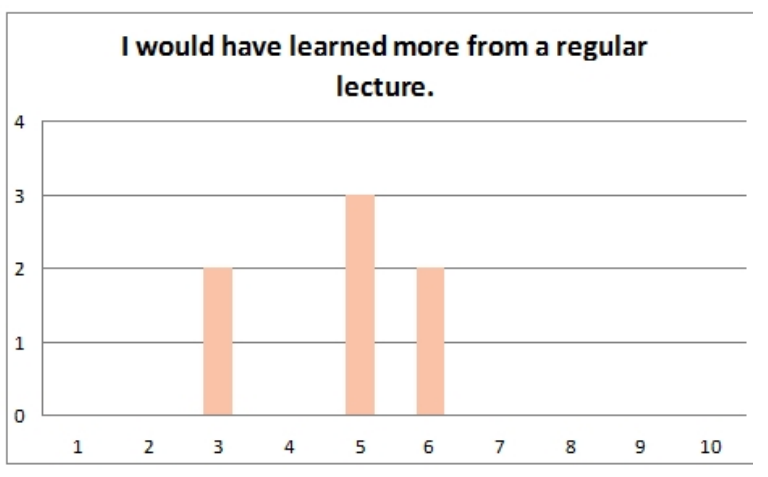

Figure 1: Evaluation by Participants
Fig. 1.b

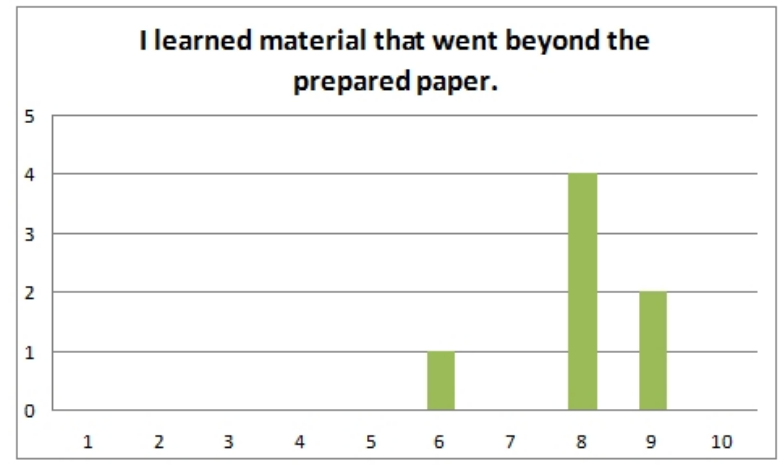

Fig. 1.d

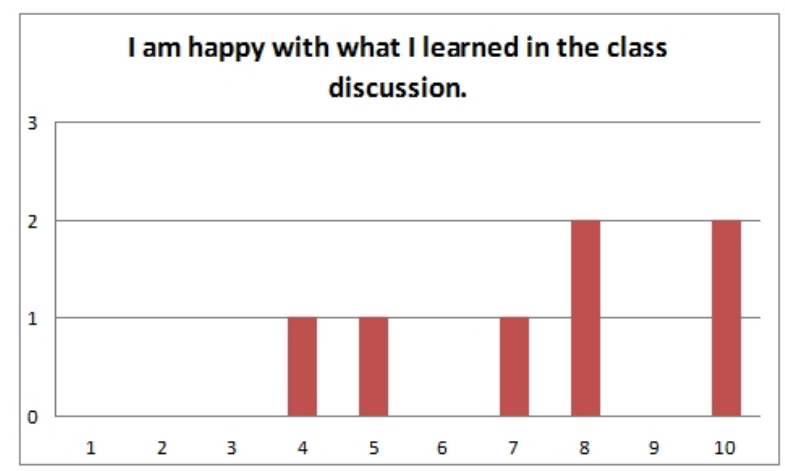

Fig. 1.f

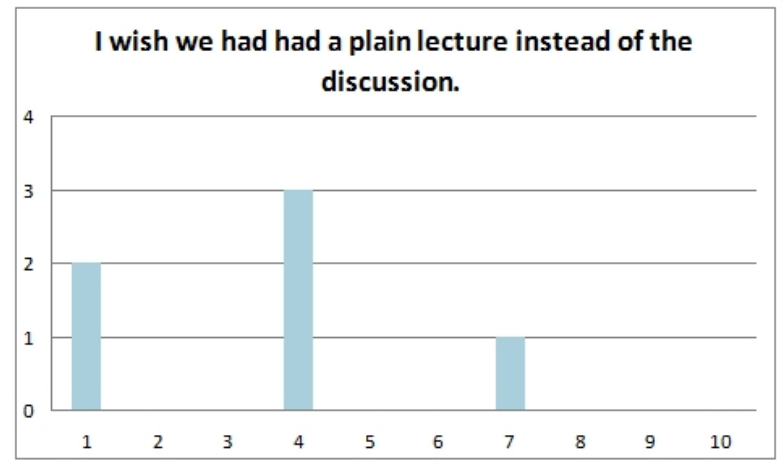


My personal impression of the panel discussion was confirmed with these survey responses as well as additional open-form feedback: Most of the students were enthusiastic about this different form of exercise. Some of the open-ended feedback was "Really nice with some change. And a good class with a good discussion." or "I liked that it was a different way of engaging with the material, whether or not more actual information was learned, it forced us to use different parts of our brains, and perhaps the material will 'stick' more."

From my own observations and the students' feedback, I will no longer feel the need to worry about exposing students to confusing material, as long as I manage their expectations and prepare them for this challenge. But, a caveat is in order: This was a relatively small group of motivated students, who had elected to participate in the discussion, and who were well prepared. A difficulty might arise when the class becomes bigger.

\subsection{Absenteeism}

Despite the apparent success of the panel discussion, it failed on one account: Attendance. Therefore, I also investigated the reasons for this high non-participation rate in the survey. I learned that $84 \%$ of students could not participate because of timing conflicts - the week of this exercise coincided with the deadline for the BA thesis submission, study excursions, and municipal elections. Only 2 students said they did not prepare sufficiently (or said they did not have enough time to prepare sufficiently). Only 1 student said he did not want to participate in the discussion exercise because "I did not feel the payoff was sufficient." Despite my initial thoughts, shyness did not cause absenteeism. The majority did not feel afraid of speaking in public (Fig.2.a), only 1 or 2 students mentioned this as a problem. Lack of motivation for the topic itself and the complexity of the discussion task were also not main drivers of absenteeism (Fig.2.b and 2.c). This means that motivation to avoid failure (Brophy, 2010) was not an issue for students. Interestingly, students' opinions on the value of a lecture versus class discussion were very divided in this full sample (not only those who had participated): Student opinions seem almost bimodal (Fig.2.d), with 36\% strongly disagreeing to "I would have preferred a lecture by the professor" and 55\% agreeing relatively strongly (7-10). 
(a)

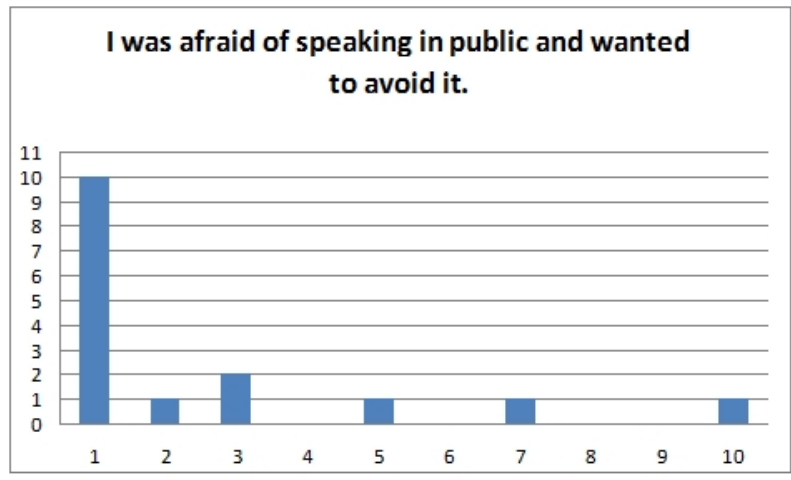

(c)

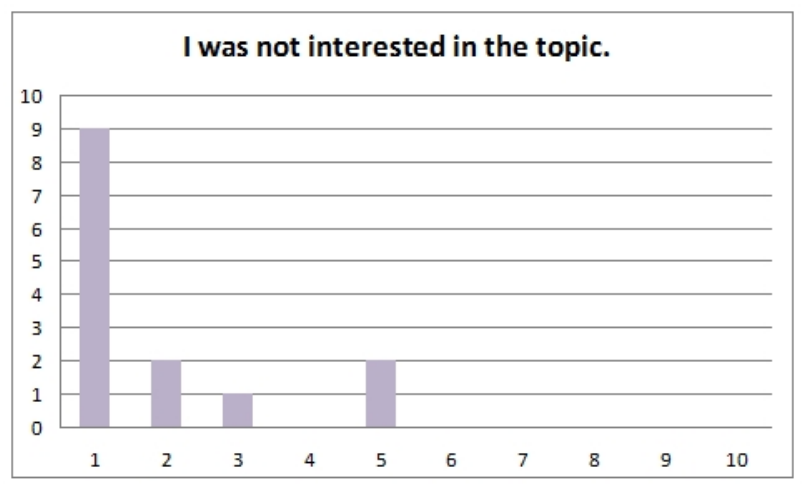

(b)

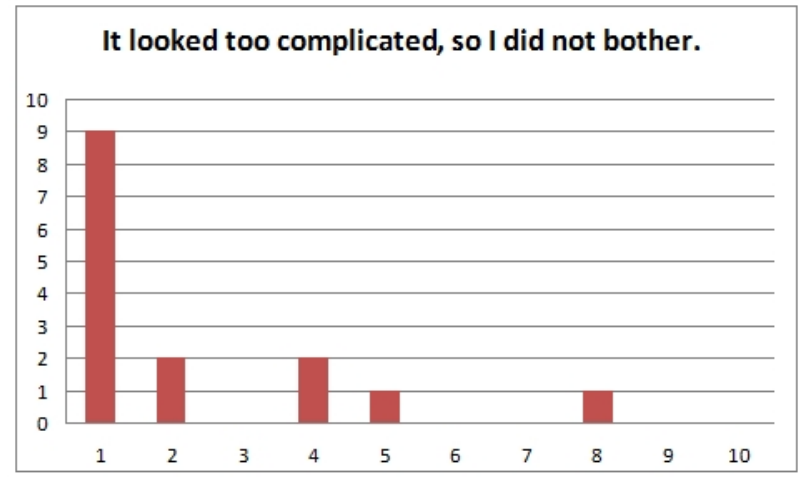

(d)

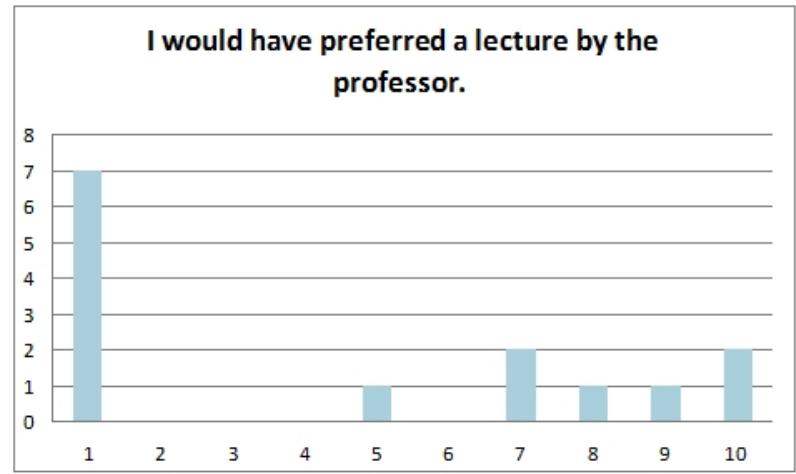

Figure 2: Nonparticipants: Reasons for Absence

The general set-up of the class itself has been confirmed to be productive, and I can recommend it for future use. For larger groups, the setting may have to change, such as having two sessions, or organizing sub-panels in one group, and asking students to hand in written summaries of their discussion as a quality check. An increase in participation can be gained from paying closer attention to timing issues such as the BA thesis deadline. But I would also encourage attendance by highlighting the value of this exercise as an opportunity for practice.

\section{Conclusion}

I conclude from this evaluation that students appreciated the opportunity to experience a topic with a different approach than regular lecturing. I saw their confidence with the discussion set-up increase, and some of the worries I had before were proven unfounded. Instead, students demonstrated improved argumentation skills, as they used the formative assessment to imitate experts, to try out their arguments in a low stakes collaborative learning setting, to learn from their own and others' mistakes. I can highly recommend panel discussions as a way to cover a topic while giving students opportunity to practice and rehearse, improving skills needed to perform well in the exam and in the real world. 
Miriam Gensowski is an assistant professor at the University of Copenhagen, Department of Economics, and an IZA Research Affiliate and HCEO Emerging Scholar. She obtained her PhD in Economics at the University of Chicago. Her research interests include labor economics, the economics of education, and applied microeconometrics. In particular, she has worked on the returns to education, wage inequality in the U.S., intergenerational occupational mobility, and the role of multi-dimensional abilities and psychological traits on occupational choice.

\section{Literature}

Becker, W. E. and M. Watts (2001). Teaching Economics at the Start of the 21st Century: Still Chalk-and-Talk. The American Economic Review 91 (2), 446-451. Biggs, J. and C. Tang (2007). Teaching for Quality Learning at University (3rd ed.). McGraw-Hill Society for Research into Higher Education \& Open University Press.

Brophy, J. (2010). Supporting Students' Confidence as Learners. In Motivating Students to Learn, Chapter 3. New York: Routledge.

Knight, P. and M. Yorke (2003). Assessment, Learning, and Employability. Open University Press.

Molloy, E. and D. Boud (2014). Feedback Models for Learning, Teaching and Performance. In J. M. Spector, M. D. Merrill, J. Elen, and M. J. Bishop (Eds.), Handbook of Research on Educational Communications and Technology, Chapter 33, pp. 412-424. New York: Springer.

Sambell, K., L. McDowell, and C. Montgomery (2013). Assessment for Learning in Higher Education. Routledge. 